\title{
Evaluation of social and environmental entrepreneurship development in Russia and Finland
}

\author{
Marina Moroshkina ${ }^{1,{ }^{*}}$, Lidiya Murashkina $^{2}$, and Marina Utistyna $^{2}$ \\ ${ }^{1}$ KarNC RAS Institute of Economics, 185030, Petrozavodsk, Russia \\ ${ }^{2}$ State and Municipal Management of the Institute of Economics and Law, 185011, Petrozavodsk, \\ Russia
}

\begin{abstract}
The presented article explores aspects of the development of social entrepreneurship within the border areas of Russia and Finland. The aim of the study is to assess the opportunities for the development of social entrepreneurship. The object of the research is the consumers of the service sector in Russia and Finland. The research method is a questionnaire survey, as a result of which the formed questions provide information about the development of the entrepreneurial sector. The study analyzes the needs and opportunities for the development of social entrepreneurship in the border areas. The assessment of the development of the sphere of social entrepreneurship uses the method of focus groups, which allows getting the analysis of the situation from the experts from Karelia and Finland. As a result of the research the differences in separate directions of development of the entrepreneurial sector in the Republic of Karelia and Finland have been revealed. The differences in the expectations of young people of the countries under consideration and the fears of Russian and Finnish respondents were determined. The obtained results allow us to determine the differences in social and economic policy of the states
\end{abstract}

\section{Introduction}

The economic development of territories depends on a significant number of factors. One of the significant factors that have an important impact on socio-economic growth is the business sector. Attention to the development of the business sector in the territories is paid by various administrative, governmental and other directions. In the context of existing forms of entrepreneurial activity, many areas are distinguished. In recent years social entrepreneurship has been developing in many countries since it allows for efficient social problem solving thanks to the combination of social and market motifs, as well as the use of innovative approaches. Social entrepreneurship is a rather new term in business spheres, both in Russia and in Finland. However, as a phenomenon it's been around for a long time, especially in Finland, where there is the rule of equal opportunity for employment for all groups of people irrespective of their physical or psychic health. In the Russian Federation the notion of "social entrepreneurship" was established by the Federal Law in July 2019. As

*Corresponding author: maribel74@mail.ru 
a result of the formed provisions for social entrepreneurship, the main areas of activity are distinguished.

The main characteristics of social entrepreneurship both in Russia and in Finland can be considered the following:

- special business models created for solving first of all social problems with a possibility for profit and commercial success.

- businesses operating on certain territories and assisting in the development of these territories.

- entrepreneurship activity aimed at the development of socially useful services for the most vulnerable and unprotected groups of people (pensioners, people with disabilities, unemployed, etc.)

According to the 2019 research "The best place to be a social entrepreneur" (The best place to be a social entrepreneur 2019 (trust.org)), published once in three years and jointly conducted by THOMSON REUTERS FOUNDATION and DEUTSCHE BANK, Finland took the eighth place among the countries with best conditions for social entrepreneurs. The countries are ranged according to 12 indicators in six categories including state support, popular understanding of social entrepreneurship, rates of development, access to investment, earning one's living with this activity and attraction of qualified personnel.

Finland topped the rankings in the last two areas, ranking first in terms of opportunities for social entrepreneurs to earn a living from their activities, and second in terms of the ease of finding employees with the necessary skills. Other important achievements in Finland were: the second place in equal pay for women leaders and the third place in access to grant funding, which showed an increase of 36 points compared to 2016.

Social entrepreneurship is implemented in different organizational forms: in Finland it's first of all NGOs. In Russia besides that different forms of individual entrepreneurship, as well as small and medium-size business, are possible.

As a result of the increased interest in the problem of social entrepreneurship, a large number of studies and scientific and practical publications analyzing this phenomenon appear. This article makes an attempt to consider the potential for development of social entrepreneurship in Russia and Finland on the basis of result analysis of focus groups with experts and studying the needs and interests of young people in the border territories.

\section{Materials and methods}

As a result of changes taking place in the world community, the interest in border territories has significantly increased [1]. In modern conditions of integration and globalization, regions actively use their advantages to stimulate the processes of economic development [2]. One of the incentives for economic growth is the location of the region, depending on which the territories have the opportunity for more active development of the business and manufacturing sector [3]. The business sector is defined by various areas that determine the format of production activities of the territory. The notion of social entrepreneurship is defined differently by researchers depending on the direction of the conducted analysis [4, 5]. It is worth noting that a great number of kinds of social entrepreneurship can be considered which is determined by the needs of the population [6].

Russian Federation is a territory with a high indicator of border territories influencing most indicators of economic development [7]. External economic connections have a great importance for the formation and functioning of the business sector [8]. This aspect is also important for the development of the social area of entrepreneurship [9, 10]. Assessment of the border situation of the territory is considered in most research works according to the economic development of the territory. 
As a result, considering the prospects for the development of social entrepreneurship in comparison with other developed countries is an important research area.

The analysis of needs and opportunities for the development of social entrepreneurship in the border areas and the creation of a register of socio-economic activities is mainly based on the method of focus groups with experts from Karelia and Finland.

The focus group method is based on conducting a group discussion resulting in determining the participants' attitude to the question under discussion. In this research we consider opportunities for social entrepreneurship within border territories. The focus group method can be used independently or in combination with other methods. The use of focus groups in the research provides an opportunity to use qualitative analysis along with quantitative data, allowing for more demonstrative results. [11]

The group of experts included established entrepreneurs, representatives of administrations from Kajaani, Oulu, Kostomuksha and Petrozavodsk, specialists from employment offices, and services working with young people in these territories, as well as representatives of municipalities support infrastructure. We managed to hold an expert seminar in Petrozavodsk in March, 2020 (see Appendix 1). However, due to the epidemic and quarantine we had to abandon live forms of communication. Instead, we actively used online interviews and webinars on the YouTube channel of the project and social networks.

In addition, an analysis of open official sources and statistics on available measures to support young people interested in social entrepreneurship was carried out.

The main source for analyzing the needs and interests of young people in the border areas was a questionnaire developed by us, which was distributed through the project's social media pages Facebook, Instagram, ВКонтакте, as well as through employment offices, educational institutions and youth centers (Survey Powered by Webropol: Опрос "Молодежь приграничного региона Финляндия - Карелия" (webropolsurveys.com).

\section{Results}

Within the set goal, the research was carried out in several stages.

Sociological characteristics of respondents. As of late June, 2020, some 236 people took part in the survey, 126 representing Finland and 110 representing the Republic of Karelia, aged 18 to 35 years.

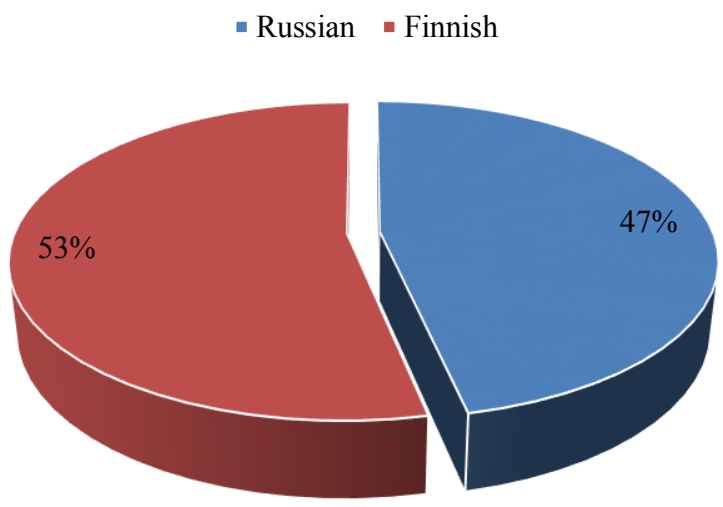

Fig. 1. Proportion of respondents.

Average age of participants - 18-24 years old (52\% and 58\%). 


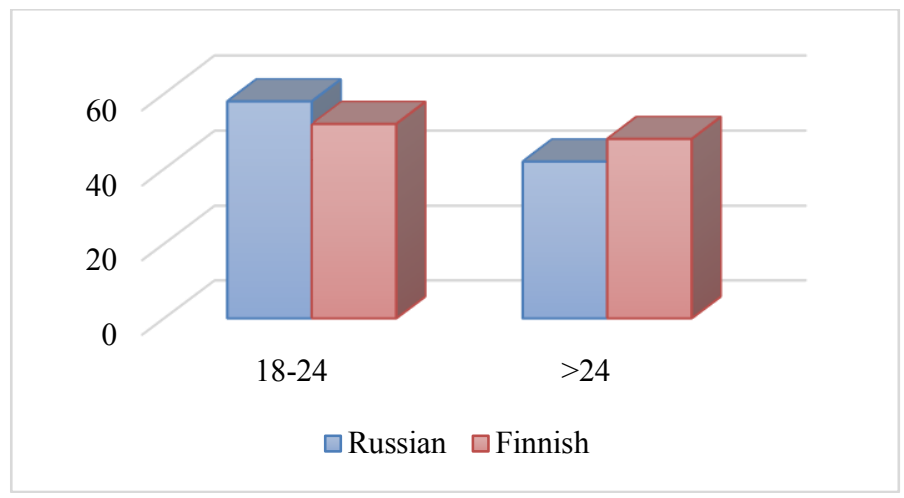

Fig. 2. Age structure of respondents.

Among them - $61 \%$ and $70 \%$ - women, $37 \%$ and $30 \%$ - men, $2 \%$ stated their gender as "other".

Most of them (69\% and 50\%) are university students. Besides, $11 \%$ and $25 \%$ have graduated and work; $5 \%$ and $1 \%$ are unemployed; $12 \%$ participants from Karelia are developing their own business. Also among the answers: "on maternity leave", "on leave caring for a child". As a result of the sociological survey, the polled respondents have a non-uniform structure.

Comparative analysis of life satisfaction in border regions of Finland and RK. As shown by the research, the living standard of the population (economic well-being, life satisfaction) is assessed much higher by respondents from Finland $(3,1)$, than those from Russia (2,2, maximum - 4).

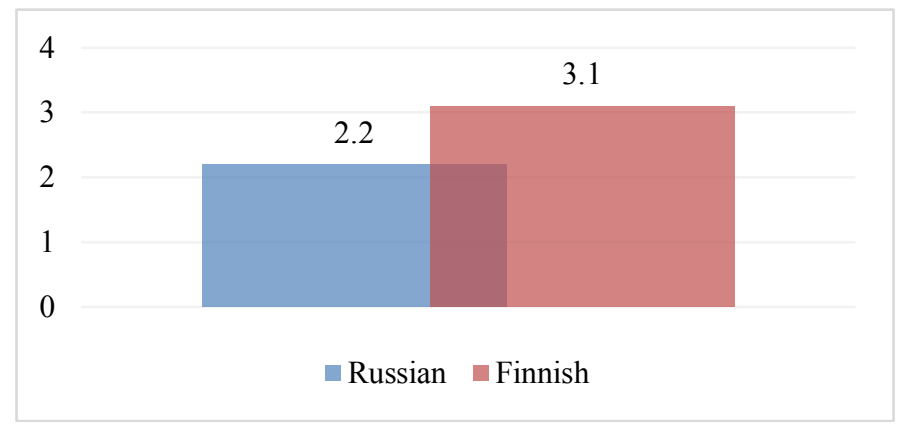

Fig. 3. Assessment of well-being by respondents.

At the same time, living conditions in the Republic of Karelia were assessed somewhat higher than in RF in total (5\% of respondents gave maximum points to RK, only $2 \%$ - for RF). Living conditions in Northern Finland, on the contrary, were assessed lower than on average in the country ( $29 \%$ against $36 \%$ correspondingly).

Life satisfaction among young people in Finland is also significantly higher than in Russia (7,1 and 5,9 points of 10; median values -8 and 6 correspondingly).

Possibilities for self-realization are seen by $58 \%$ Finnish respondents and $39 \%$ respondents from Karelia, the share of undecided (answer "I don't know") is approximately evenly high: $23 \%$ in Finland and $21 \%$ in Karelia.

Expectations, concerns and needs of the youth living in border territories. Border areas have a special status and special opportunities for economic development. As a result of the study of border territories, the main expectations of the active part of the population were evaluated. 
For the Finnish youth, the main expectations (aspirations) from life look as follows: to have an interesting job (66\%), to get good education $(53 \%)$, to realize oneself creatively $(50 \%)$.

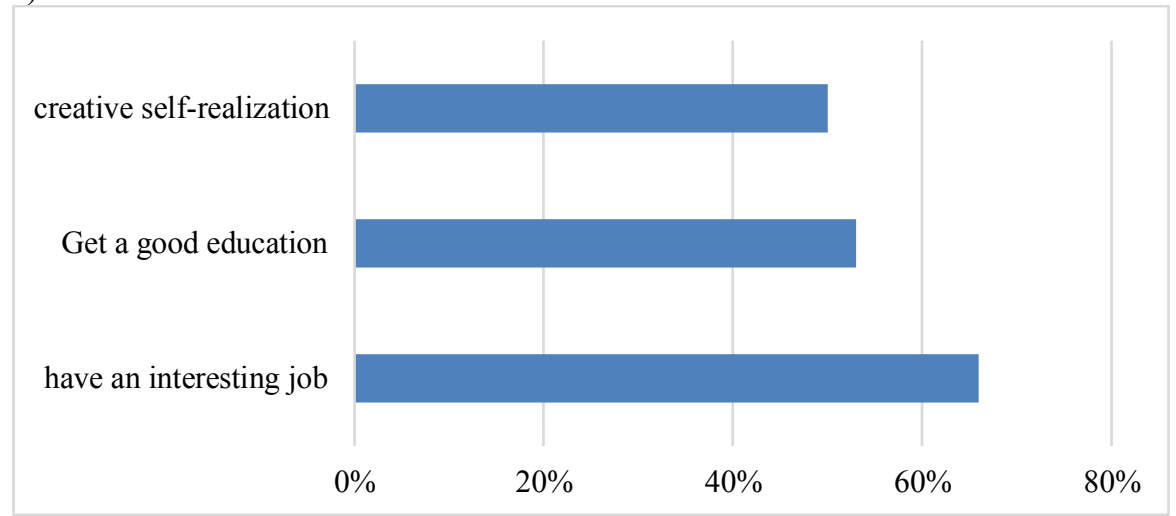

Fig. 4. Expectations of Finnish youth.

According to the respondents from Karelia, the three main expectations are: to achieve material well-being (67\%), to get a well-paid job (59\%), to have an interesting job (38\%), to get a good education (38\%).

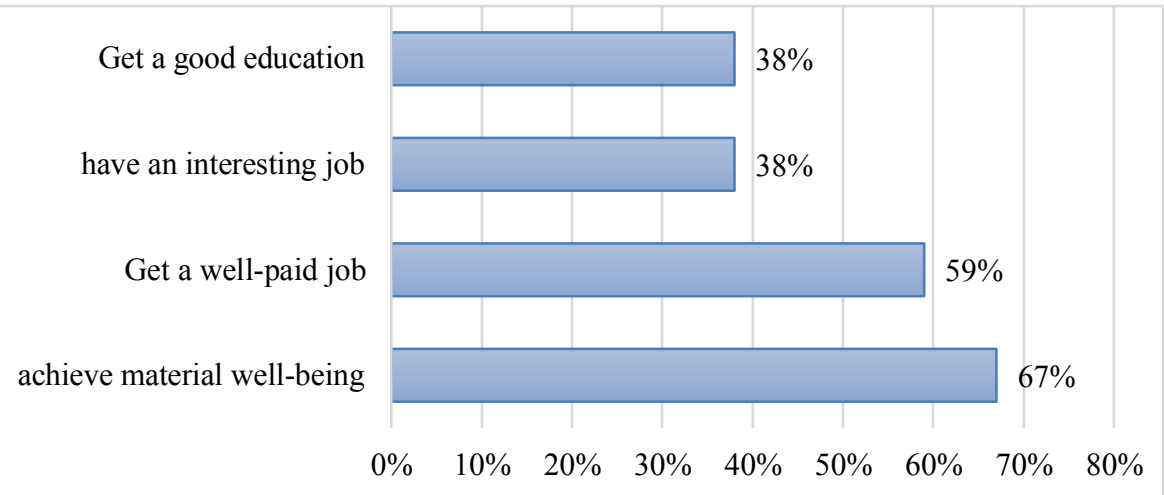

Fig. 5. Expectations of Russian youth.

The option "start my own business" was chosen by $27 \%$ respondents from Karelia and 8\% from Finland.

In general, the expectations of young people living in the border areas are about the same, and relate to education and interesting and well-paid work in the future. It can also be concluded that for Finnish youth, the desire for creative self-realization is more important than the desire to achieve material well-being. This correlates with the first block, in which life satisfaction in Finland (including material well-being) is significantly higher than in the Russian Federation. This also explains that the main concern for the young people of Karelia is "to be left without any material means for existence" - 71\% respondents (against $39 \%$ from Finland). About the same number of young people is concerned about their future, their life and their relatives $-52 \%$ in Russia and $51 \%$ in Finland. The third place among Russian respondents is occupied by worrying about limitations on behalf of the state - $39 \%$ (and only 9\% among Finnish respondents). For Finnish respondents on the third place are concerns related to problems of finding a job $-53 \%$ (against $36 \%$ for survey participants from Karelia). Significant concerns of the Finnish youth are related to the social connections: $42 \%$ are afraid to be left without friends (against $17 \%$ among 
participants from Karelia) and 31\% of Finnish respondents are concerned about not ever meeting a person they love (against $20 \%$ from Karelia).

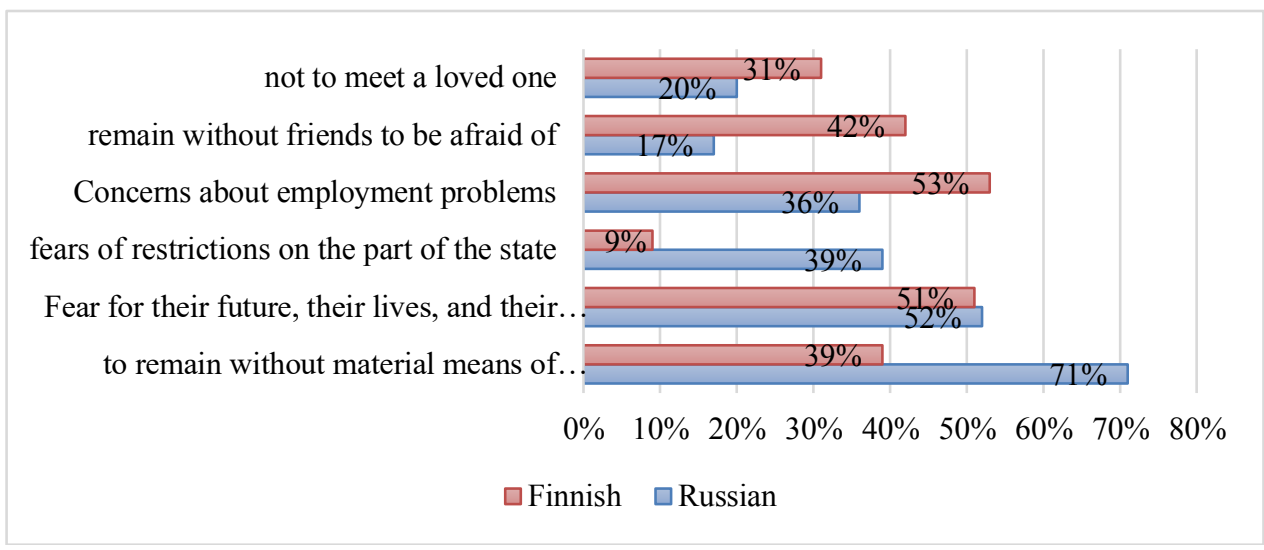

Fig. 6. Concerns of Russian and Finnish respondents.

Answers to the question "what do young people lack?" (needs) were surprisingly almost the same among Finnish and Russian respondents:

In the first place was the need for leisure areas (58\% Finnish participants and 49\% participants from Karelia).

In the second place was the need for educational events $(34 \%$ and $39 \%$ correspondingly).

And in the third place with the same percentage of votes $(37 \%)$ was the need for public sites.

The biggest difference between Finnish and Russian respondents was in such positions as: need for parks (15\% and 31\% correspondingly), need for meaningful leisure events for young families with children (25\% and $34 \%$ correspondingly), support for youth movements (23\% and 30\% correspondingly), support in cultural enlightenment (34\% and $29 \%$ correspondingly), lack of entertainment (30\% and $24 \%$ correspondingly) and sports grounds (20\% and $26 \%$ correspondingly).

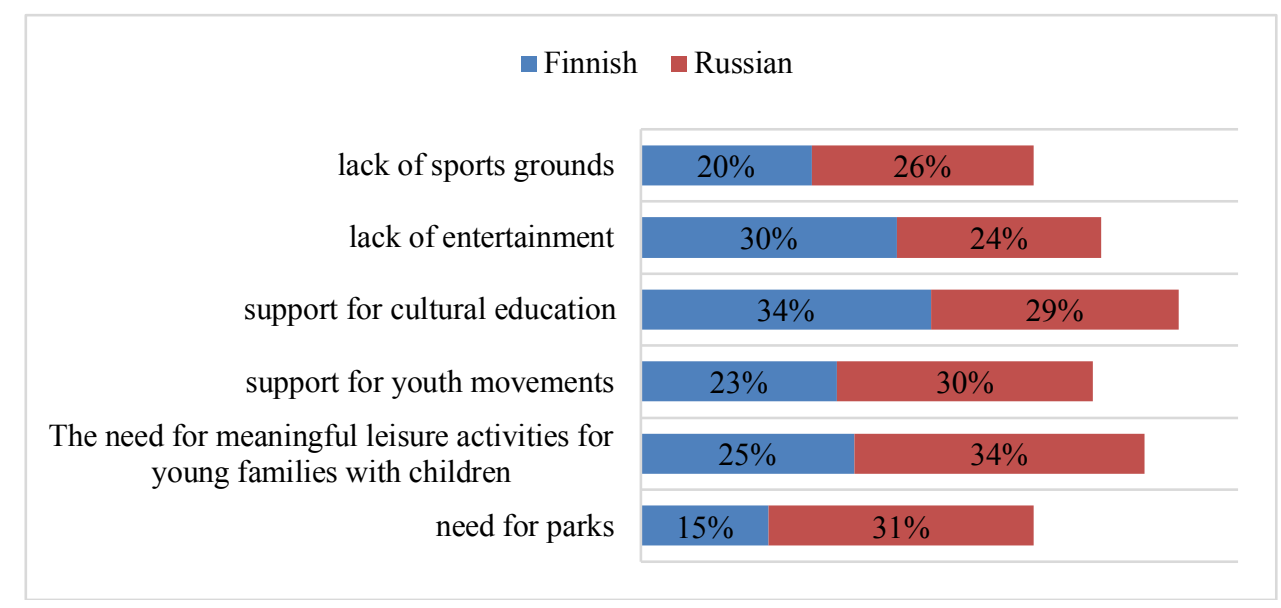

Fig. 7. The needs of respondents in Russia and Finland. 


\subsection{Planning for a decade}

Since one of the goals and missions of social entrepreneurship is the emergence of socially useful services involved in the sustainable development of specific territories, we could not help but ask questions about the immediate plans of young people for life. The most popular both for Finnish and Russian young people were the following answers:

- to engage in self-education and self-development (60\% and $81 \%$ correspondingly);

- to find a well-paid job (74\% and 52\% correspondingly).

In the third place among the Finnish youth was the answer: "To move to another city permanently" - 33\% (28\% among respondents from Karelia), but for Russian participants, in the third place was the answer: "to start/open my own business" - 44\% (16\% respondents from Finland).

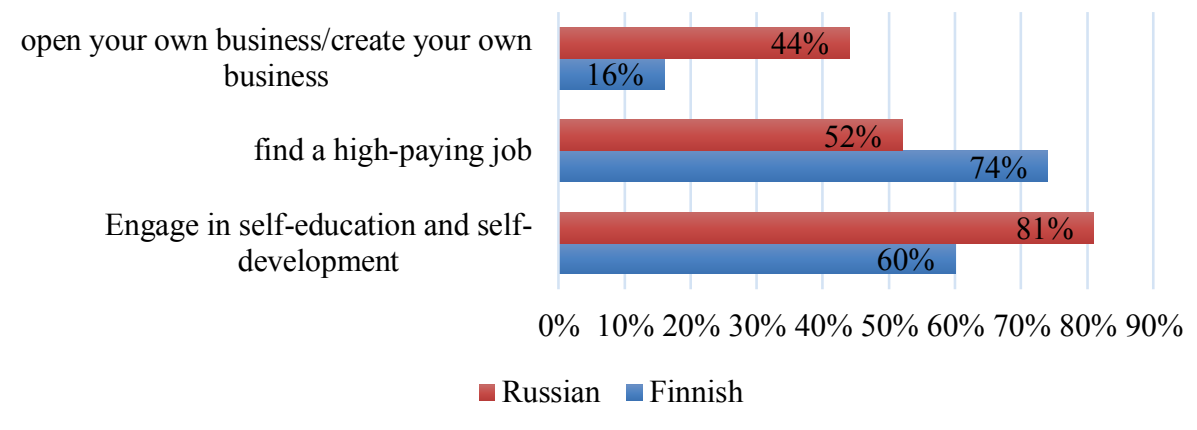

Fig. 8. Long-term priorities of Finnish and Russian youth.

Answers to the question "Are you going to stay where you live now?" on both sides were similar: $42 \%$ Finnish participants and 36\% participants from the Russian side have not decided yet. $24 \%$ of Finnish participants are going to move, and 34\% respondents from Karelia. Those planning to stay $-34 \%$ and $30 \%$ correspondingly. Those who would like to start their own business where they live now: 18\% Finnish respondents and 43\% Russian. Unfortunately, this idea does not look attractive to the Finnish youth; 57\% responded negatively ( $30 \%$ from the Russian side), undecided are $25 \%$ and $27 \%$ correspondingly.

Among the risks related to starting their own business, the Finnish young people mentioned concerns that the business would not be profitable - 32\% (15\%), Russian participants are not sure of financial stability when opening their own business - $36 \%(22 \%$ correspondingly). Also, among the top three popular answers were "not enough information about business" - 13\% Finnish respondents $(5 \%)$, are afraid to choose a non-profitable business niche $-18 \%$ Russian participants (4\%). Rather high risk is also related to the fact that business can deprive one of free time - 9\% Finnish participants (and 6\% correspondingly), 9\% Finnish and 4\% Russian participants have an idea, but they do not know what to do next. 9\% Russian participants (and 1\% correspondingly) mention the lack of support programs for startups. 
no support programs for start-ups

there is an idea, but do not know what to do next

business can deprive free time

fear choosing a profitable business niche

little information on "business"

lack of confidence in financial sustainability when opening a business

fears that business will not generate income

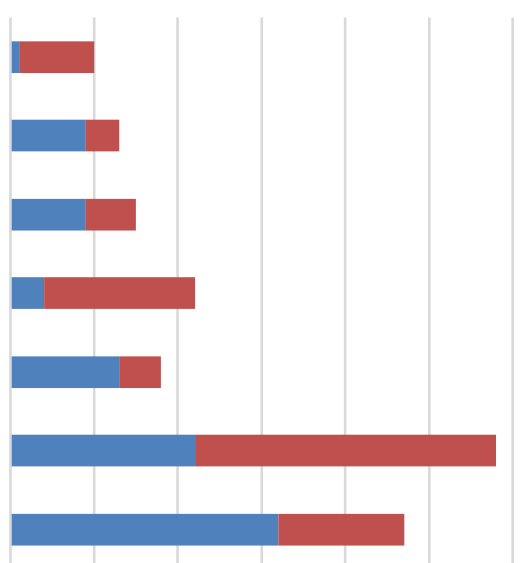

$\begin{array}{llllllll}0 \% & 10 \% & 20 \% & 30 \% & 40 \% & 50 \% & 60 \% & 70 \%\end{array}$

Finnish Russian

Fig. 9. Risks related to starting own business.

It is thought that living in a border area is a bonus for starting one's own business, and $51 \%$ Russian participants (15\%) agree with this; most Finnish respondents never thought about it $-57 \%$ (33\% correspondingly). 28\% of Finnish respondents and 16\% Russian participants do not agree with this statement. At the same time, $41 \%$ respondents from Karelia and 14\% Finnish participants are interested in starting a joint business. Never thought about it $-41 \%$ and $32 \%$ correspondingly. Unfortunately, this idea does not attract a great number of young people $-45 \%$ and $27 \%$ correspondingly. The main risks of starting a joint business according to $39 \%$ Finnish participants are difficulties from the legal point of view (great differences in legislation, etc.), but 50\% Russian participants have no information about starting joint businesses (15\% correspondingly). Also among the risks of stating a joint business are concerns for not finding partners on the other side $(10 \%$ Finnish respondents and 23\% Russian), and concerns for financial stability (10\% Finnish respondents and 7\% Russian). Additional answers to this question from Karelian participants mentioned concerns for administrative barriers and obstacles on behalf of the customs and government. Finnish participants, however, mentioned risks related to the language barrier, differences in culture (including business culture), as well as political situation in RF.

At the same time, 37\% Finnish participants and 40\% Russians would like to be engaged in social entrepreneurship, but $23 \%$ and $30 \%$ correspondingly do not know that it is.

The most attractive spheres for creating socially beneficial services look as follows:

- education, science (60\% Finnish participants and 32\% Russian)

- culture, arts (48\% and 29\%)

- tourism $(32 \%$ and $31 \%)$

- environment and animal protection (34\% and 23\%)

- leisure, sports $(31 \%$ and $28 \%)$

- health care $(23 \%$ and $16 \%)$

- information systems, mass media (19\% and 12\%)

- social work, social protection (12\% and $22 \%)$

- protection of political, economic and social rights (15\% and 19\%)

- domestic services ( $9 \%$ and 16\%) 
Besides, additional answers included the following: agriculture, architecture and building, entertainment sphere and socially beneficial services in the area of supporting people with mental problems.

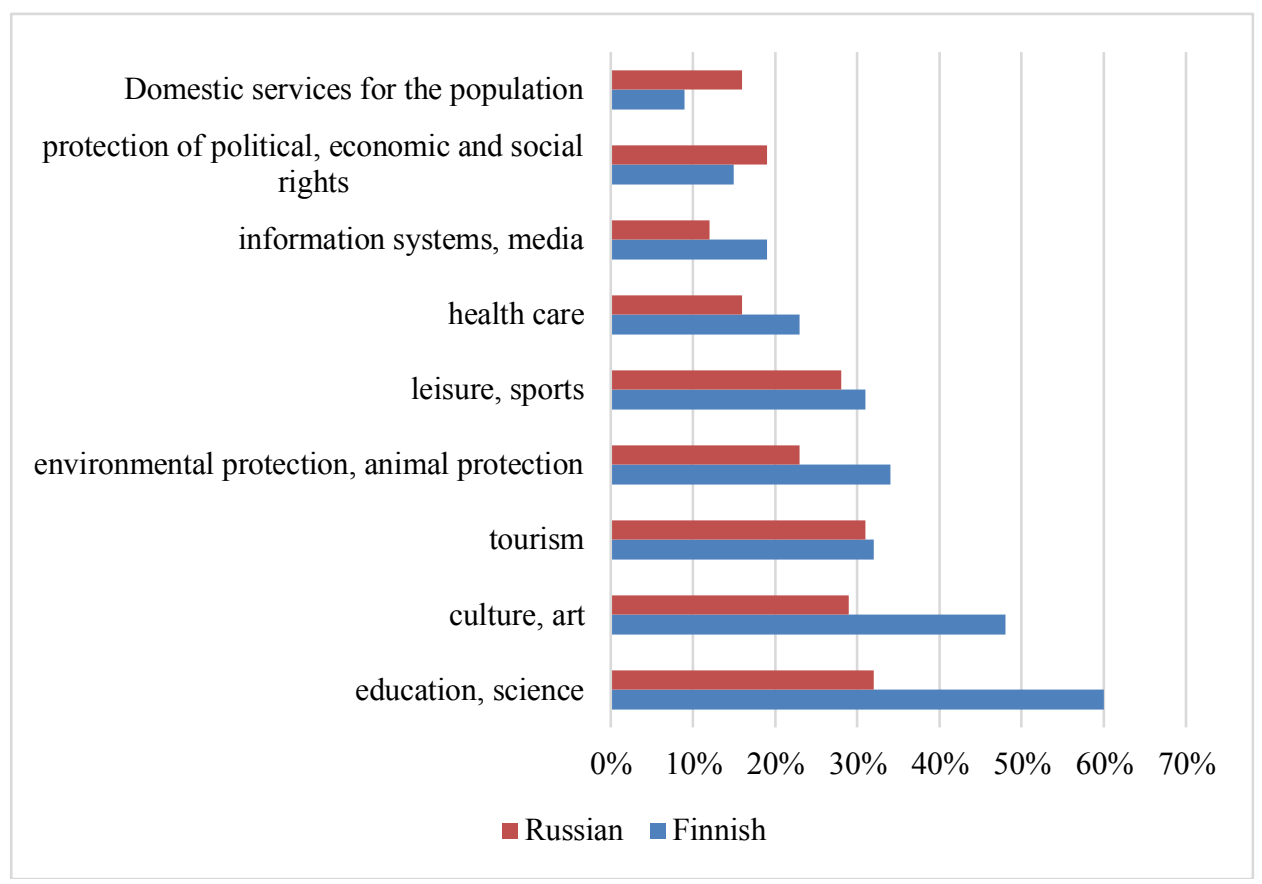

Fig. 10. Areas for creation of socially beneficial services.

\section{Conclusion}

The conducted research on certain areas of development of the business sector in the Republic of Karelia and Finland has identified various trends. As part of the survey, it was revealed that life satisfaction is estimated by respondents from Finland much higher than by respondents from the Russian Federation, which can be explained by a higher standard of living of the population. The expectations of young people in the countries under consideration also differ significantly. For Finnish youth, the main motivation is the search for an interesting job. For the Russian young generation the main expectation from future labor activity is achieving material well-being. The conducted research revealed that concerns of Russian and Finnish respondents are different. The obtained results may be connected with differences in social and economic policy of the states in question.

\subsection{Captions/numbering}

The industrially developed Orenburgskaya oblast $(124000 \mathrm{~km} 2)$ is located in the central part of the Eurasia's steppe zone; on the south it surrounds the Ural Mountains. A crossing of the Ural mountainous-plain country and the steppe zone conditioned a wide range and wealth of natural resources, including land, that had promoted an active agrarian and industrial development of the area beginning the middle part of XVIII century. The territory has been developing agriculturally simultaneously with the industrialization in 1930-1970- 


\section{Acknowledgement}

The work was done as part of the budget research work at the Institute of Economics of the Karelian Scientific Center of the Russian Academy of Sciences (№ AAAA-A19119010990087-1).

\section{References}

1. B. Demeterova, B. Goodwin-Hawkins, T. Fischer, European Planning Studies 28(12) (2020) https://doi.org/10.1080/09654313.2020.1716692

2. A. Purdeková, Memory Studies https://doi.org/10.1177/1750698018800749

13(6) (2020)

3. Yu.G. Tyurina, M.A. Troyanskaya, Economics, entrepreneurship and law 9(4) (2019) doi: 10.18334/epp.9.4.41531

4. A.P. Pinto, K.J. Reshma, Journal of Engineering Education Transformations 34, (2021) DOI: $10.16920 /$ jeet/2021/v34i0/157227

5. Y.E. Blagov, Y.N. Aray, Social Enterprise Journal 15(2) (2019) https://doi.org/10.1108/SEJ-05-2018-0043

6. A. Paraskevopoulou, A. Klados, C. Malesios, Sustainability 12(23) (2020) https://doi.org/10.3390/su12239976

7. S.V. Stepanova, Baltic Region 11(2) (2019) https://doi.org/10.5922/2079-8555-2019$2-6$

8. G. Ocskay, Territorial Impact Assessment. Advances in Spatial Science (The Regional Science Series) (2020) https://doi.org/10.1007/978-3-030-54502-4_7

9. A. Popov, T. Soloveva, Sovremennaya Evropa 1 (2020) DOI: http://dx.doi.org/10.15211/soveurope12020170181

10. D. Pletnev, E. Nikolaeva, E. Silova, E3S Web of Conferences 13014, 210 (2020) doi:10.1051/e3sconf/202021013014

11. B. Grüning, Journal of Classical Sociology (2020) https://doi.org/10.1177/1468795X19900667 